\title{
An objective assessment of synovitis of the knee: measurement of the size of the suprapatellar pouch on xeroradiography
}

\author{
J. M. GUMPEL, SARAH A. MATTHEWS, D. G. ALTMAN, ${ }^{1}$ \\ J. D. SPENCER, ${ }^{2}$ AND E. A. WILKINS ${ }^{2}$
}

From the Rheumatic Diseases Study Group, the ${ }^{1}$ Division of Computing and Statistics, and the ${ }^{2}$ Department of Radiology, Northwick Park Hospital and Clinical Research Centre, Harrow

SUMMARY Measurement of the size of the suprapatellar pouch of the knee appears to be a simple, useful, objective, and reproducible assessment of synovitis of the knee. Changes in the apparent size of the suprapatellar pouch have been shown to correlate closely with the volume of synovial fluid aspirated from the knee and with changes in circumferential measurements. Aspiration of $20 \mathrm{ml}$ of fluid will produce a change in size significant at the $1 \%$ level. Lateral xeroradiographs were used in this study, as soft-tissue planes are more closely defined on xeroradiographs than on standard radiographs.

Few simple and objective assessments of disease activity in rheumatoid arthritis are available. Two are frequently used and have withstood the test of time: the articular index ${ }^{1}$ and measurement of proximal interphalangeal joint size. ${ }^{2}$ Both have wellknown limitations; in particular, the articular index is most reproducible in the presence of widespread active and relatively untreated disease, while changes of joint size will occur only if they are reversible. In a discussion on measurement in rheumatoid arthritis Hart and Huskisson ${ }^{3}$ suggested that 'the ideal measurement is one which can be quickly made without complex or expensive apparatus. It should be stable, but sensitive enough to show the effects of active drugs. It should have some relevance to the practising clinician and should closely parallel relevant parameters such as pain and stiffness, the relief of which is the objective of treatment'.

Numerous other objective assessments such as joint thermography and quantitative isotope scans have been described: most involve expensive equipment and skilled personnel, and fail to be reproducible unless used under ideal conditions. Furthermore, there are suggestions that the changes observed with thermography and with quantitative isotope scanning do not occur in parallel with other methods

Accepted for publication 20 June 1979

Correspondence to $\mathrm{Dr}$ J. M. Gumpel, Northwick Park Hospital, Watford Road, Harrow, Middlesex HA1 3UJ. of assessment. ${ }^{4}$ Simple techniques, such as grip strength and knee circumference measurements, are often used. But grip strength is not wholly objective, and while knee circumferences ${ }^{6}$ are reproducible when measuring normal knees, the changes observed in clinical practice rarely exceed the inherent inaccuracies of the measurements? ${ }^{7}$. As a result clinical trials in rheumatoid arthritis rely heavily on subjective impressions of improvement by patient and physician.

The knee is the joint most commonly involved first in rheumatoid arthritis ${ }^{8}$ and tends to remain the joint most commonly requiring individual therapy, such as intra-articular injection or synovectomy. An objective and reproducible assessment of synovitis of the knee would be highly desirable. Soft-tissue swelling of the knee may often be easily recognised on conventional radiographs, ${ }^{9}$ but in a comparison of surgical synovectomy and intraarticular irradiation ${ }^{10}$ the soft-tissue swelling of the suprapatellar pouch was so variably represented on routine radiographs that it could not be included as an assessment (Renton P, personal communication). The superior visualisation of soft-tissue planes on xeroradiographs offers the potential of an accurate and repeatable measurement of soft-tissue swelling as well as an estimate of articular damage in rheumatoid arthritis. Lovell et al. ${ }^{11}$ compared the changes seen on radiographs and xeroradiographs of the hand in rheumatoid arthritis. They found little 
overall difference. Osteoporosis was reported more frequently on conventional $x$-rays, and loss of joint space and synovial thickening on xeroradiographs.

In this study we have investigated the reliability of assessments of soft-tissue swelling of the knee on xeroradiographs. These were taken before and after aspiration and the changes were compared with the volume of synovial fluid aspirated and with the associated difference in measurements of the circumference. The reproducibility of this assessment has also been analysed.

\section{Patients, materials, and methods}

The patients studied were those attending a rheumatology clinic who had chronic synovitis of the knee requiring therapeutically indicated aspiration and corticosteroid injection. Lateral xeroradiographs were taken before and after aspiration, and if swelling persisted were repeated at standard intervals. The same observer (S.A.M.) took duplicate measurements of the circumference of the 37 knees at midpatellar level (M-P level) and at $1 \mathrm{~cm}$ above the upper border $(1 \mathrm{~cm}$ above) before and after aspiration of the knee and at the time of interval xeroradiographs and recorded a clinical assessment of the degree of synovitis. Synovial fluid could be aspirated in 12 knees; the net quantity removed was recorded.

An estimate of the size ('area') of the suprapatellar pouch was obtained from the xeroradiographs by multiplying the length of the pouch by its maximum breadth. Measurements of the xeroradiographs were made by the same observer (R.W.) throughout, without knowledge of clinical details. Changes in this 'area' were related to changes in the circumference and to the volume of synovial fluid aspirated in 11 knees. No postaspiration xeroradiograph was taken in 1 knee. In order to check that comparable xeroradiographic appearances could be obtained when fluid was present in the knee without an accompanying synovitis, xeroradiographs were taken in 1 post-mortem subject with different quantities of fluid in the knee.

The xeroradiographs were taken with a standard focus film distance of $120 \mathrm{~cm}$. Positive mode ' $D$ ' charge xeroradiography was used at $120 \mathrm{kVp} .{ }^{12}$ The most common exposure was $25 \mathrm{~mA}$ using a carbon fibre cassette. Xeroarthrography was performed using Conray 280, with the contrast material diluted $1: 4$ or $1: 5$, where possible in a volume equivalent to that aspirated.

Finally, in order to measure reproducibility the components of variance in the measurement of the suprapatellar pouch were calculated. Three observers (J.M.G., J.D.S., R.A.W.) measured the size of the suprapatellar pouch on the preaspiration and postaspiration films of 10 knees, and on a subsequent film of 9 of these 10 knees. The films were read in a different random order on 2 occasions, with 1 week between readings, without knowledge of the identity of the subject or of the sequence of the films. To ensure that observers made comparable measurements in this experiment the lower end of the suprapatellar pouch was defined on an anatomical basis.

\section{STATISTICAL METHODS}

Reproducibility was investigated by means of a 2-way analysis of variance of a random effects model, and from this 4 components of variance were obtained. ${ }^{13}$ These correspond to interpatient $\dot{\omega}$ variation $\left(\mathbf{s}^{2} \mathbf{p}\right)$, interobserver variation $\left(\mathbf{s}^{2} \mathbf{o}\right)$, observer- \&ु patient interaction $\left(\mathrm{s}^{2} \mathrm{op}\right)$, and intraobserver variation $ᄋ$ $\left(s^{2}\right)$. The interaction was minimal and was added to the interpatient variation in Table 2.

The variance of a single observation by a specific observer on a specific patient is just $\mathrm{s}^{2}$, and the $\stackrel{\infty}{\rightarrow}$ variance of the difference between 2 such measure- $\vec{\theta}$ ments $x_{1}$ and $x_{2}$ taken on separate occasions is given $\stackrel{\infty}{\circ}$ by

$$
\operatorname{var}\left(x_{1}-x_{2}\right)=\operatorname{var}\left(x_{1}\right)+\operatorname{var}\left(x_{2}\right)=2 s^{2} r
$$

(where $x_{1}$ and $x_{2}$ are assumed independent) and the standard error is thus $s_{r} \sqrt{2}$. If $x_{1}$ and $x_{2}$ are each the mean of two observations, $\operatorname{var}\left(x_{1}-x_{2}\right)=s_{r}^{2}$ and the standard error is $s_{\mathbf{r}}$.

The critical difference (CD) is used to assess $\overrightarrow{\overrightarrow{0}}$ changes in a measurement between occasions. It is given by $\mathrm{U} \times$ standard error where $\mathrm{U}=1.96$ for a $5 \% \mathrm{CD}$ or 2.58 for a $1 \% \mathrm{CD}$. The percentage is the

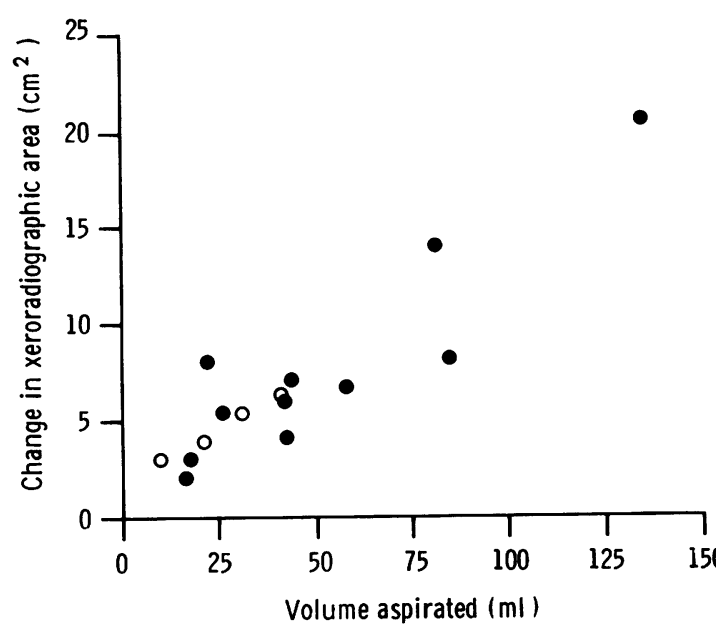

Fig. 1 Relationship between the change in the volume of synovial fluid aspirated and the change in xeroradiographic area. The open circles represent the post-mortem subject. $r=0.90$ 
probability that the $C D$ will be exceeded when there has not been any real change in the measurement.

To obtain a CD for the case where the observers of $x_{1}$ and $x_{2}$ are different the variance of a single observation was taken as $\mathbf{s}_{\mathbf{r}}^{2}+\mathbf{s}^{2}$.

\section{Results}

Clear and statistically significant relationships were found between the volume of fluid aspirated with

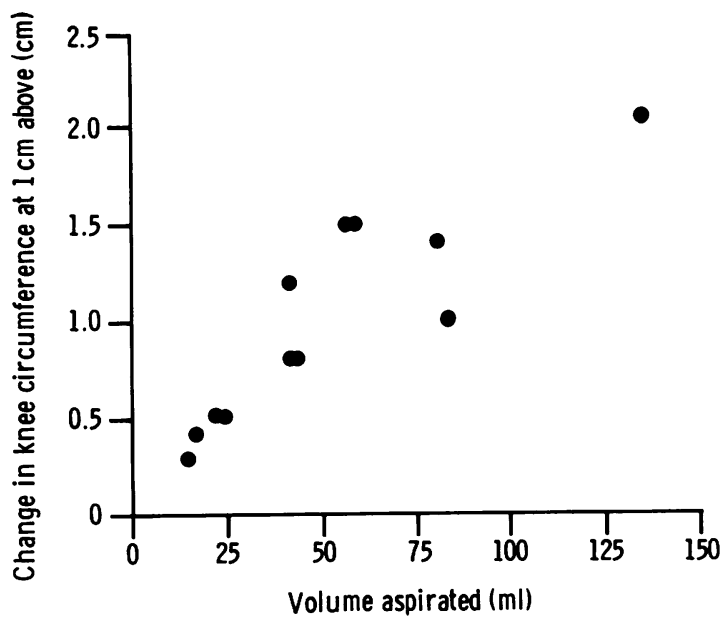

Fig. 2 Relationship between the change in circumference $1 \mathrm{~cm}$ above the patella and the volume of fluid aspirated. $r=0.88$

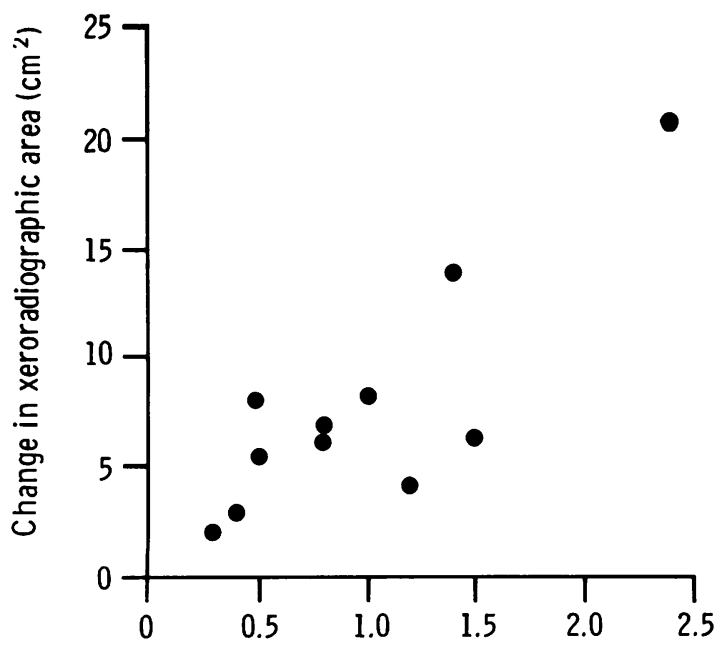

Change in knee circumference at $1 \mathrm{~cm}$ above $(\mathrm{cm})$

Fig. 3 Relationship between the change in xeroradiographic area and the change in circumference at midpatellar level. $r=0.82$ the charge in xeroradiographic area of the suprapatellar pouch (Fig. 1) and with the change in circumference of the knee $1 \mathrm{~cm}$ above the knee (Fig. 2). Also shown in Fig. 1 are the four points obtained in the post-mortem subject with increasing volumes of fluid in the knee which fit well with the in-vivo results. The change in xeroradiographic area of the suprapatellar pouch correlated well with the change in circumference $1 \mathrm{~cm}$ above the knee (Fig. 3). Less satisfactory correlations were obtained when the change in xeroradiographic area and the volume aspirated were compared with the change in midpatellar circumference (Figs. 4 and 5). In pre-

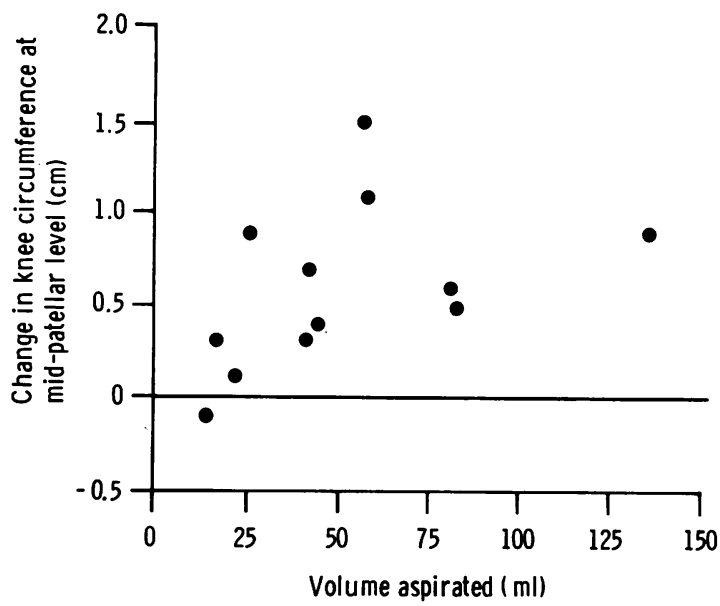

Fig. 4 Relationship between the volume of fluid aspirated and the change in circumference at midpatellar level. $r=0.42$

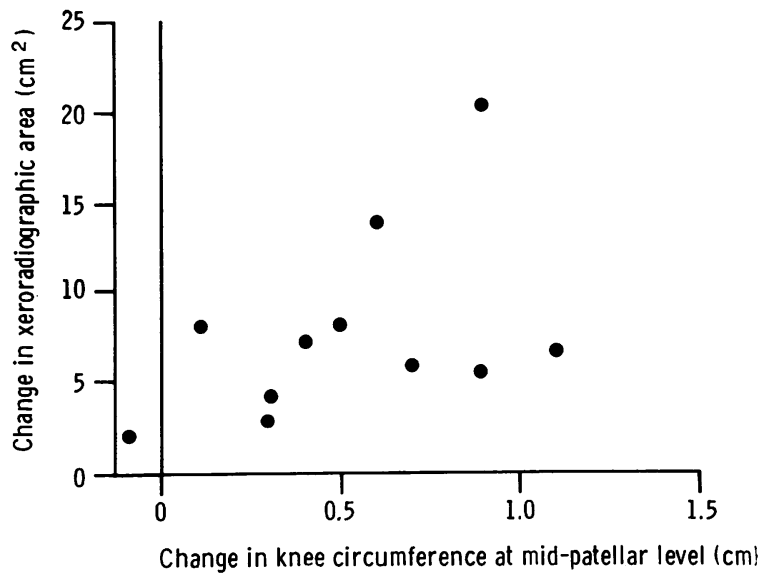

Fig. 5 Relationship between the change in xeroradiographic area and the change in circumference at midpatellar level. $r=0.41$ 
vious work the latter had proved less satisfactory than the circumference $1 \mathrm{~cm}$ above the patella. These findings and their statistical significance are summarised in Table 1 . As the subsequent work on reproducibility suggested that measurement of length was more accurate than breadth, the correlations between length and the other variables are also shown in Table 1.

Examples of the xeroradiographs obtained in this study are shown in Figs. 6, 8, and 10. Xeroarthrograms were occasionally performed, particularly

Table 1 Correlation coefficients between the changes in area of the suprapatellar pouch on xeroradiographs, volume of synovial fluid aspirated, and change in measurements at midpatellar level and $1 \mathrm{~cm}$ above. $n=11$ or 12

\begin{tabular}{llllll}
\hline Volume & & & & & \\
Area & 0.90 & & & & \\
Length & 0.78 & 0.91 & & & \\
$+1 \mathrm{~cm}$ & 0.88 & 0.82 & 0.70 & & \\
Midpatellar & 0.42 & 0.41 & 0.33 & 0.53 & \\
& Volume & Area & Length & $+1 \mathrm{~cm}$ & MP \\
\hline
\end{tabular}

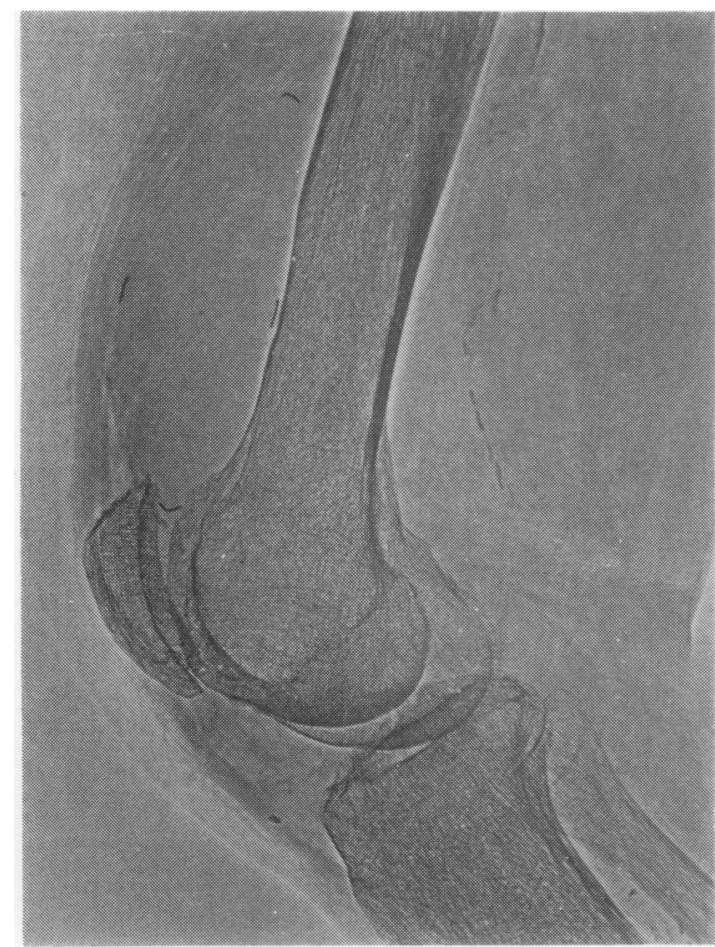

Fig. 6 Lateral xeroradiograph showing the suprapatellar pouch partly outlined. Unfortunately the film is not a true lateral of the knee, but with a pouch of this size this does not create a measurement problem to show whether the residual swelling after aspiration was due to synovial hyperplasia or to intraarticular fibrin (Figs. 7 and 9). Comparison of the lateral xeroradiograph of one patient (Fig. 8) with a lateral film on the xeroarthrogram (Fig. 9) shows that the measured area corresponds with the synovial swelling beneath the conjoint tendon of the quadriceps muscle.

The outline of the suprapatellar pouch could be $\vec{\circ}$ easily recognised in 70 out of 87 successive lateral $\overrightarrow{\vec{H}}$ xeroradiographs. On 2 postaspiration films no $\stackrel{\omega}{\Omega}$ suprapatellar swelling could be seen, while the largest pouch was $14 \mathrm{~cm}$ long and $5 \mathrm{~cm}$ wide. In some of the 17 films the pouch was visible but not clearly defined; occasionally the films were not true laterals, and on one film the pouch extended beyond the edge of the xeroradiograph. Problems of measurement occurred if the degree of flexion varied markedly from the optimum of $135^{\circ}$.

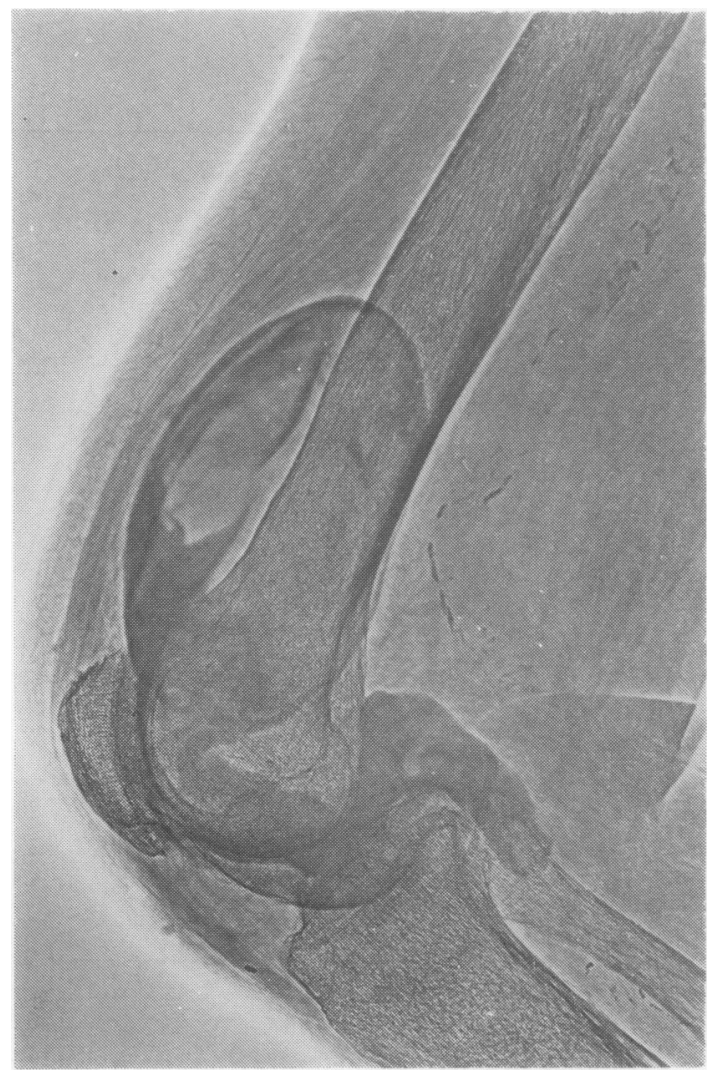

Fig. 7 Xeroarthrogram of same patient outlining the suprapatellar pouch, a Baker's cyst, and demonstrating the presence of intra-articular fibrin 


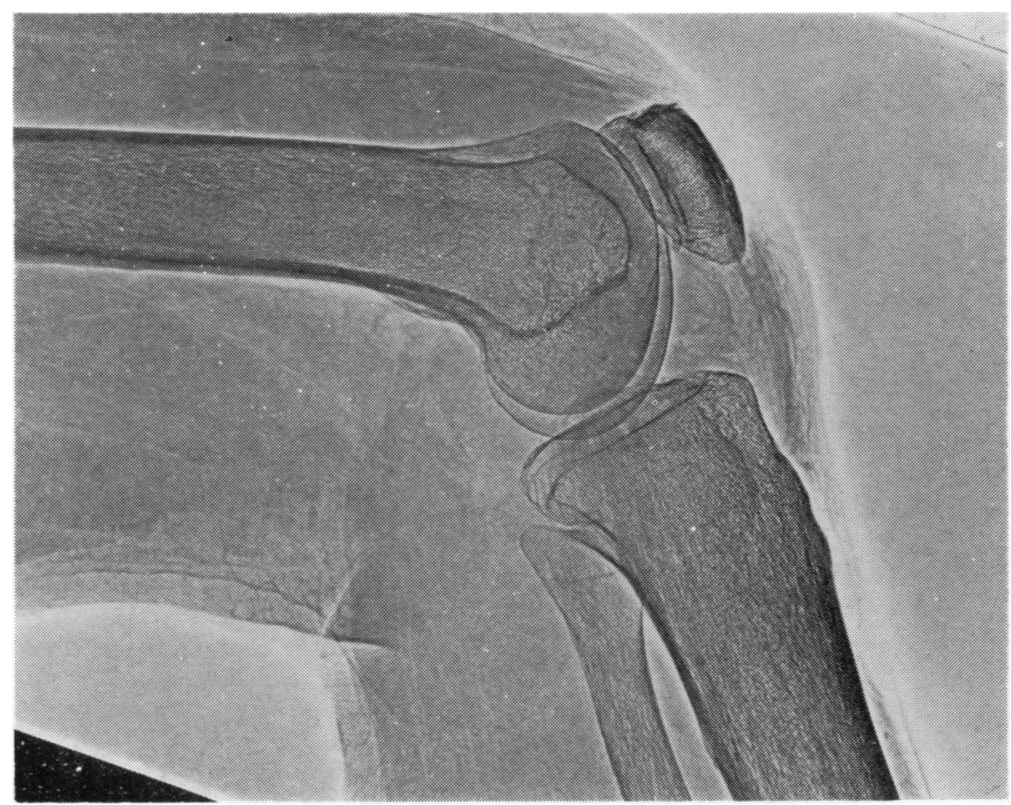

Fig. 8 Lateral xeroradiograph of a patient with a suprapatellar pouch of the size more commonly encountered in this study

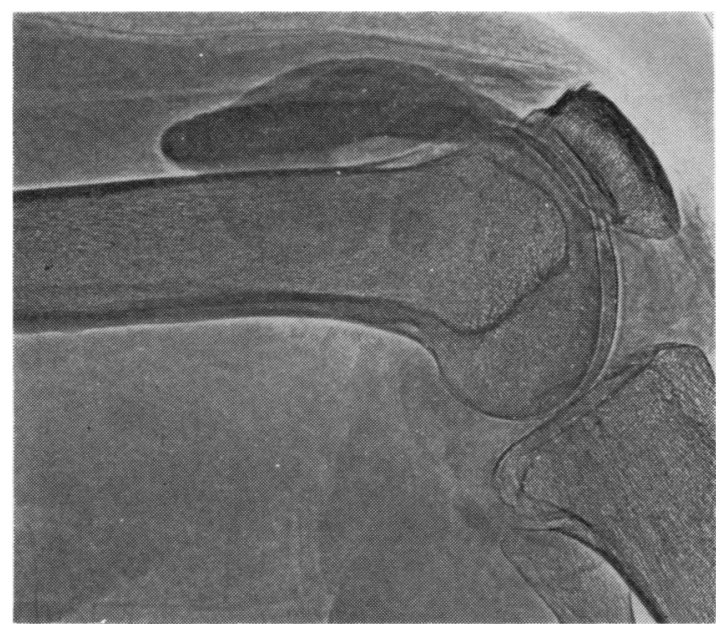

Fig. 9 Xeroarthrogram of patient in Fig. 8. Besides the central dense area which corresponds to the area measured on the lateral xeroradiograph, contrast medium can also be seen above and to the sides of the conjoint tendon and alongside the femur

\section{REPROD UCIBILITY}

Of the 29 films 1 postaspiration xeroradiograph was read as showing no suprapatellar swelling on all 6 occasions. This film was omitted from the analysis. The remaining 28 films were representative of the 87 films in the study; the mean length of the pouch was $8 \cdot 75 \mathrm{~cm}$ (range $2 \cdot 1-12 \cdot 0 \mathrm{~cm}$ ) mean breadth
$1 \cdot 95 \mathrm{~cm}(0 \cdot 6-3 \cdot 3 \mathrm{~cm})$ and the mean area $18 \mathrm{~cm}^{2}$ $\left(1 \cdot 26-39 \cdot 6 \mathrm{~cm}^{2}\right)$. The 28 films could be divided into two groups: 17 films in which the suprapatellar pouch was clearly defined and measurement was simple, and 11 in which the observers thought that minor interobserver differences in making measurements might have been more likely.

The components of variance obtained from the duplicate measurements of the size of suprapatellar pouch on 28 films are shown in Table 2. The loss of precision for the less satisfactory films was less than the observers would have expected. Critical differences for both area and for length derived from the components of variance for all 28 films are shown in Table 3.

Table 2 Components of variance for measurement of length, breadth, and area of suprapatellar pouch for all 28 films and by technical quality

\begin{tabular}{|c|c|c|c|c|}
\hline & & $\begin{array}{l}\text { All films } \\
(n=28)\end{array}$ & $\begin{array}{l}\text { Good } \\
(n=17)\end{array}$ & $\begin{array}{l}\text { Poor } \\
(n=I I)\end{array}$ \\
\hline \multirow[t]{4}{*}{ (a) } & Length $(\mathrm{cm})$ & & & \\
\hline & Interpatient & $6 \cdot 284$ & 7.451 & $4 \cdot 770$ \\
\hline & Interobserver & 0.021 & 0.019 & 0.021 \\
\hline & Intraobserver & 0.045 & 0.034 & 0.062 \\
\hline \multirow[t]{4}{*}{ (b) } & Breadth $(\mathrm{cm})$ & & & \\
\hline & Interpatient & 0.412 & 0.483 & 0.223 \\
\hline & Interobserver & 0.009 & 0.005 & 0.016 \\
\hline & Intraobserver & 0.010 & 0.010 & 0.010 \\
\hline \multirow[t]{4}{*}{ (c) } & Area $\left(\mathrm{cm}^{2}\right)$ & & & \\
\hline & Interpatient & $73 \cdot 085$ & $87 \cdot 509$ & $37 \cdot 859$ \\
\hline & Interobserver & $1 \cdot 152$ & 0.881 & $1 \cdot 582$ \\
\hline & Intraobserver & $1 \cdot 080$ & $1 \cdot 253$ & 0.816 \\
\hline
\end{tabular}




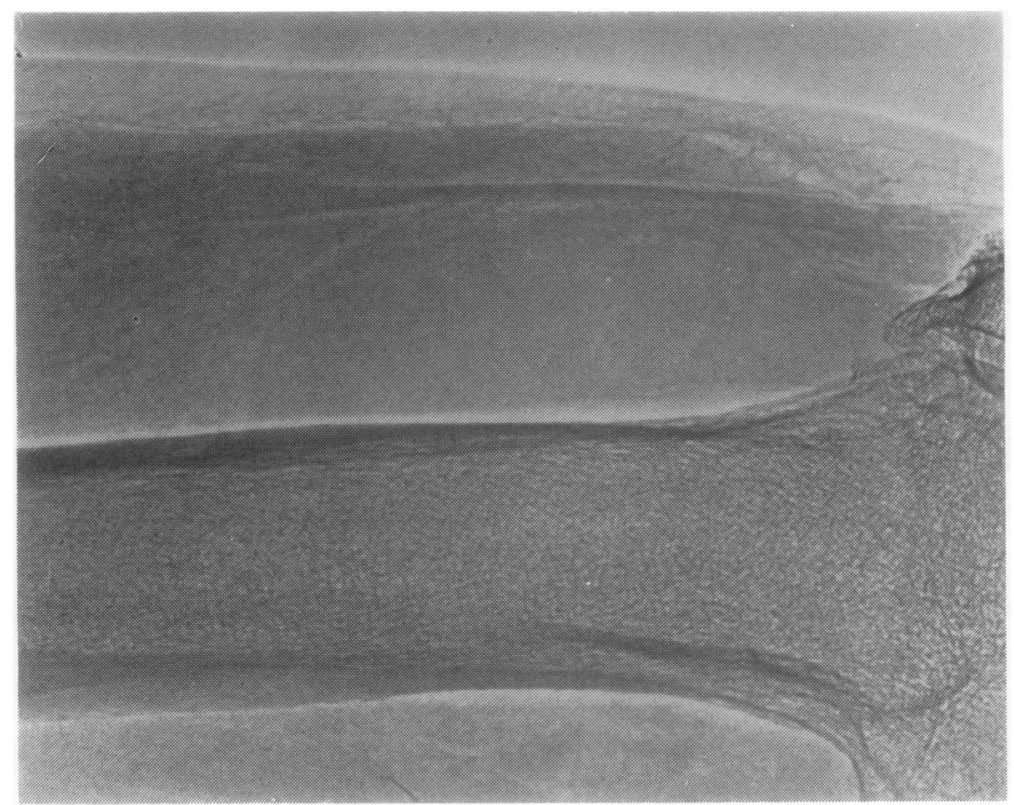

Fig. 10 Lateral xeroradiograph to show a dense suprapatellar pouch which is clearly outlined. Problems in measurement occur because of the large osteophyte on the superior end of the patella. The anatomy is shown on the attached diagram: patella-P, suprapatellar osteophyte-O quadriceps muscle- $Q$, quadriceps tendon-T. The superior end of the

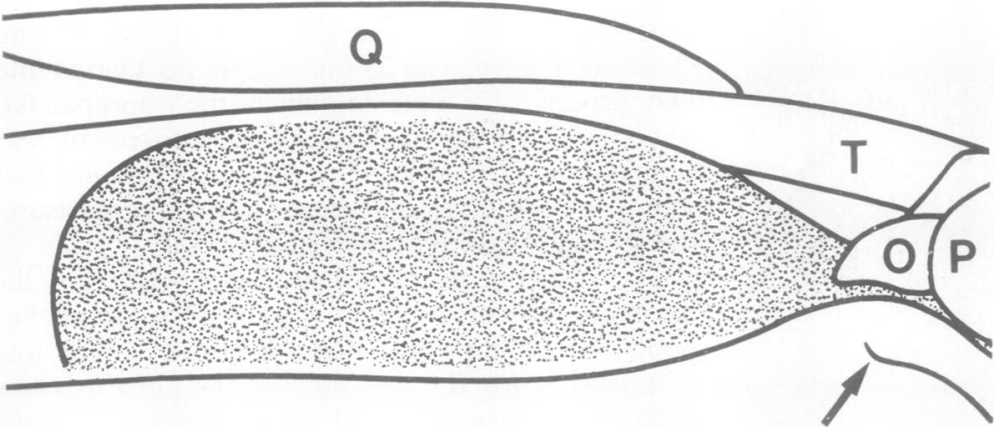
intercondylar line is indicated.

Table 3 Critical difference (5\% and $1 \%$ ) for assessing changes in length and area of supratellar pouch (calculated from data from all 28 films)

\begin{tabular}{|c|c|c|c|c|c|c|}
\hline & & \multirow{2}{*}{$\begin{array}{l}\text { Variance } \\
\text { of a single } \\
\text { obser- } \\
\text { vation }\end{array}$} & \multicolumn{2}{|c|}{$\begin{array}{l}\text { Single } \\
\text { measurement }\end{array}$} & \multicolumn{2}{|c|}{$\begin{array}{l}\text { Mean of } 2 \\
\text { measurements }\end{array}$} \\
\hline & & & $5 \%$ & $1 \%$ & $5 \%$ & $1 \%$ \\
\hline $\begin{array}{l}\text { Area } \\
\left(\mathrm{cm}^{2}\right) \\
\text { Length } \\
(\mathrm{cm})\end{array}$ & $\begin{array}{l}\text { Same observer } \\
\text { Different observers } \\
\text { Same observer } \\
\text { Different observers }\end{array}$ & $\begin{array}{l}1 \cdot 080 \\
2 \cdot 232 \\
0.045 \\
0.066\end{array}$ & $\begin{array}{l}2 \cdot 88 \\
4 \cdot 14 \\
0 \cdot 59 \\
0 \cdot 71\end{array}$ & $\begin{array}{l}3 \cdot 79 \\
5 \cdot 45 \\
0 \cdot 78 \\
0 \cdot 93\end{array}$ & $\begin{array}{l}2 \cdot 04 \\
2 \cdot 93 \\
0.42 \\
0.50\end{array}$ & $\begin{array}{l}2 \cdot 68 \\
3 \cdot 85 \\
0 \cdot 55 \\
0 \cdot 66\end{array}$ \\
\hline
\end{tabular}

When these critical differences are applied to the data derived from the 11 patients in Figs. 1-3, in only 1 was the change in area or length less than the $1 \%$ critical difference, this being the subject with the less amount of synovial fluid aspirated $(15 \mathrm{ml})$.

\section{Discussion}

Measurement of the size of the suprapatellar pouch would appear to be a suitable objective measure of synovitis of the knee. As such, it would be useful as part of a general assessment of rheumatoid arthritis and particularly in the context of treatment of the knee. One particular advantage over clinical assessments, circumferential measurements, and some methods of isotope scanning and thermography is that the original data remain available for retrospective analysis and for comparison with subsequent data. The technique of measurement is simple and can be done by any competent observer, and the inter- and intraobserver variations are minimal. 
All but 1 of the criteria of Hart and Huskisson ${ }^{3}$ appear to be amply fulfilled. The exception is that subjective relief and reduction of the size of suprapatellar swelling were usually but not invariably associated. The change in the size of the suprapatellar pouch correlated well with the quantity of synovial fluid, an absolute measurement, and also with circumferential measurements. It has considerable advantages over both. Synovial fluid is only 1 component of the swelling, and could be aspirated in only 12 of the 37 knees in this study, a not uncommon finding in chronic synovitis. Residual swelling after aspiration represents the thickened synovial membranes together with intraarticular fibrin.

Circumferential measurements provide only a relative assessment of synovial inflammation and in long-term studies may be seriously affected by changes in weight or in muscle bulk. While relatively reproducible in normal individuals, they are considerably less so in patients with clinical involvement of the knee.

In another study on circumferential measurements ${ }^{7}$ the minimum change in size of the knee sufficient to produce a change of statistical significance was equivalent to the aspiration of $40 \mathrm{ml}$ of fluid. A change of this size will occur only in a small proportion of patients. With measurement of the suprapatellar pouch the corresponding change is equivalent to the aspiration of $20 \mathrm{ml}$ reflecting the better reproducibility of this method. In practical terms this means that the change in size of suprapatellar pouch was of statistical significance at the $1 \%$ level in 10 of the 11 subjects, whereas the change in circumference $1 \mathrm{~cm}$ above the patella was not significant even at the $5 \%$ level in 6 of the 11 subjects. In this context the information obtained in the post-mortem subject is of particular interest. The quantities of fluid used were smaller than would have produced a statistically significant increase in circumferential measurements, yet they produced a steady increase in the size of the suprapatellar pouch on the xeroradiographs, which were very similar to the changes seen with withdrawal of fluid in abnormal knees.

For accurate measurement of the suprapatellar pouch careful definition of the margins is necessary. The superior and posterior margins presented little difficulty. In practice the anterior margin also presented little difficulty provided that the observer measured to the conjoint tendon of the quadriceps muscle rather than attempting to measure the bulges on either side of the tendon, as shown in the arthrogram. The inferior border should be defined anatomically as the superior part of the patella or the upper end of the intercondylar articular surface.
When the margins were thus defined, a marked increase in the accuracy and reproducibility of measurements was noted, as not all the xeroradiographs in this study had been taken with a standard degree of flexion of the knee. The choice of the product of length and breadth seemed reasonable, and correlated well with the changes in volume of fluid and suprapatellar circumference. But measurement of the length of the pouch was more precise than of breadth, particularly when measuring xeroradiographs in which the definition of the pouch was less clear, and length may well be a preferable measurement in that it is quicker to measure and correlated nearly as well as area with the volume aspirated.

Any measurement of a three dimensional object on a 1 or 2 dimensional basis is clearly a compromise. The size and shape of the suprapatellar pouch and any associated Baker's cysts could be measured by computerised axial tomography but only if this is combined with arthrography. Cooper ${ }^{14}$ has shown that Baker's cysts and by inference suprapatellar swelling cannot be visualised on CAT scans without arthrography, whereas they are visible in xeroradiographs without arthrography.

Xeroradiography of the knee is associated with an increased radiation dose compared with conventional radiographs. As demonstrated by Weston, ${ }^{9}$ it is possible to obtain satisfactory images of periarticular structures by using fine grain radiographic film, but the technique requires a low kilovoltage $x$-ray tube and special facilities for developing the film. ${ }^{15}$ In addition the exposure factors have to be precisely chosen because of the reduced film latitude. On conventionally exposed radiographs the suprapatellar pouch was so variably shown that measurement of its size was not practical in a previous study (Renton, personal communication). The good response of xeroradiography to high kilovoltages, together with the increased exposure latitude, make it an ideal system for a busy general radiology department. Although the radiation dose to the patient with xeroradiography is roughly twice that of conventional film/screen combinations, ${ }^{16}$ the properties of edge enhancement and clear demonstration of soft-tissue planes are of considerable advantage in clinical studies of rheumatoid arthritis.

Ultrasound can be used to demonstrate the suprapatellar pouch and this was done in a number of patients in this study. It has the advantage of being noninvasive and has no radiation exposure, but the interpretation required a greater degree of expertise and we felt involved a greater degree of subjective interpretation. It was also not possible to replace arthrography by using ultrasound to differentiate between synovial fluid, synovial hyperplasia, and 
intra-articular fibrin in the chronically swollen knee (Meire $\mathrm{H}$, personal communication).

\section{Conclusion}

Of the various methods available for assessment of synovitis of the knee, measurement of the size (either area or length) of the suprapatellar pouch of the knee on xeroradiography appears to be the best compromise between simplicity and reproducibility. Conventional radiographs taken with particular care may provide the same information.

We thank Mrs Carole Martin for her help in co-ordinating this study. Dr Sarah Matthews and Mrs Martin received financial support from the North-west Thames Regional Health Authority. We thank the radiographers at Northwick Park Hospital for their attention to detail.

\section{References}

1 Ritchie D M, Boyle J A, McInnes J M, Jasani M K, Dalakos T G, Grieveson P, Buchanan W W. Clinical studies with an articular index for the assessment of joint tenderness in patients with rheumatoid arthritis. $Q J$ Med 1968; 37: 393-406.

2 Boardman P L, Hart F D, Clinical measurement of the anti-inflammatory effects of salicylates in rheumatoid arthritis. Br Med J 1967; 4: 264-268.

3 Hart F D, Huskisson E C. Measurement in rheumatoid arthritis. Lancet 1972; $1: 28-30$.

4 Paterson J, Watson W S, Teasdale E, Evans A L, Newman P, James W B, Pitkeathley D A. Assessment of rheumatoid inflammation in the knee joint. Ann Rheum Dis $1978 ; 37$ : 48-53.

5 Remans J, Berghs H, Drieskens L, Kiebooms L, Polderman J. Proximal interphalangeal arthroscintigraphy in rheumatoid arthritis. Ann Rheum Dis 1978; 37: 440-443.

6 Nicholas J J, Taylor F H, Buckingham R B, Ottanello D. Measurement of the circumference of the knee with ordinary tape measures. Ann Rheum Dis 1976; 35: 282284.

7 Kirwan J R, Byron M A, Winfield J, Altman D G, Gumpel J M. Circumferential measurements in the assessment of synovitis of the knee. Rheumatol Rehabil 1979 ; in press.

8 Short C L, Bauer W, Reynolds W E. Rheumatoid Arthritis, Chapter 16. Cambridge, Mass., 1957.

9 Weston W J. The extra-synovial and capsular fat pads on the posterior aspect of the knee. Skeletal Radiol 1977; 2: 87-93.

10 Gumpel J M, Roles N C. A controlled trial of intraarticular radiocolloids versus surgical synovectomy in persistent synovitis. Lancet 1975 ; 1 : 488-489.

11 Lovell C R, Brock M, Jayson M I V, Baddeley $H$. Xeroradiography in assessment of the rheumatoid hand. Ann Rheum Dis 1977; 36: 464-467.
12 Spencer J D, Hill I D. Imaging factors for xeroradiography of the extremities. Br J Radiol 1979; 52: 51-55.

13 Snedecor G W, Cochran W G. Statistical Methods, Chapter 12. 6th ed, Iowa University Press, 1967.

14 Cooper R A. Computerised tomography (body scan) of Baker's cyst. J Rheumatol 1978; 5: 184-189.

15 Deichgraber E, Olsson B. Soft tissue radiography in painful shoulder. Acta Radiol. Diagn 1975; 16: 393-400.

16 Boag J W, Stacey A J, Davis R. Radiation exposure to the patient in xeroradiography. Br J Radiol 1976; 49: 253-261.

A D DEND U M (February 1980)

Since this paper was written xeroradiography has not become more widely available in the UK. We have therefore encouraged our radiographers in the last year to take lateral radiographs of the knee so that the suprapatellar pouch is more likely to be clearly seen (machine centred proximal to joint, different film-screen combinations). The same 3 observers read 18 radiographs and 4 xeroradiographs 3 times each by the same criteria. One radiograph of a patient with no clinical effusion was included, as in the original paper. To exclude the possibility that the original 3 observers had 'learnt' from reading xeroradiographs, they were also read once by another radiologist ( $\mathrm{Dr} \mathrm{N}$. Mitchell). The size (and range of size) of the suprapatellar pouch on the radiographs was comparable to those read in the main study.

\section{Results}

On 11 of the 18 radiographs the errors in measurement were comparable to those in the main paper, and all 4 observers agreed that no suprapatellar swelling was present on 1 radiograph. On 3 radiographs there were major differences in measurement of length, both intra- and interobserver, and in a further 3 , with smaller effusions, there was complete disagreement between observers and occasional intraobserver disagreement on whether a suprapatellar swelling was or was not present.

On 2 radiographs and on the corresponding xeroradiographs a double outline could be seen, which might be interpreted as corresponding to synovial effusion as the inner outline and synovial hyperplasia as the outer.

\section{Comment}

Clearly xeroradiography is superior to conventional radiographs for this purpose. This is particularly marked with smaller effusions, which are overlapped by the posterior parts of the quadriceps muscle. Considerably greater difficulty in interpretation and measurement with radiographs was experienced than with xeroradiographs.

We have not presented a table of components of variance for 3 reasons. An analysis based only on 11 or 14 would be misleading. Differing radiographic techniques may not allow our results to apply in other hospitals, and in any case the total disagreement on 3 radiographs and major differences in 3 films suggest that the problems are of interpretation rather than of measurement. 